\title{
A BIODANZA E A CONSTRUÇÃO DE ESTILOS DE VIDA
}

\author{
Recebido em: 10/10/2010 \\ Aceito em: 02/03/2011 \\ Denise Salgado Ribeiro dos Santos ${ }^{1}$ \\ Claudineide Cândida da Silva ${ }^{2}$ \\ Maria Aparecida Dias ${ }^{3}$ \\ Maria Isabel Brandão de Souza Mendes ${ }^{4}$
}

\begin{abstract}
RESUMO: O presente artigo investiga como as vivências integradoras da Biodanza afetam o estilo de vida de um grupo investigado de Biodanza, localizado em Natal, tendo como objetivos buscar compreender o que é vivenciar a Biodanza para os participantes; além de refletir sobre as mudanças significativas na vida dos participantes a partir das vivências integradoras. A contribuição para a área da Educação Física é a possibilidade de contribuir com os poucos trabalhos abordando a Biodanza, uma vivência que oportuniza um auto-conhecimento, uma sensibilidade do corpo-sujeito. Trata-se de uma investigação do tipo estudo de campo de natureza qualitativa, sendo o instrumento utilizado o questionário com perguntas abertas individuais para cada um dos participantes (incluindo a facilitadora) e um questionário específico somente para a facilitadora. Com base nos objetivos propostos acima e nos questionários, foram elaborados quatro itens, caracterização dos grupos, perfil sócio-economico do grupo investigado, significados da Biodanza e contribuição da Biodanza nos estilos de vida do grupo investigado, para a discussão e reflexão dos resultados. Verificou-se que a Biodanza, altera os estilos de vida dos participantes de forma sutil e significativa, propiciando estilos de vida ativos, dinâmicos, relaxantes, integrados, sensíveis, indo ao encontro de uma Educação Física que foge de modelos para o corpo, para a saúde, mas que busca reconstruir a identidade própria dos seres na sociedade.
\end{abstract}

PALAVRAS-CHAVE: Estilo de vida. Atividades de Lazer. Dança.

\section{THE BIODANZA AND THE BUILDING OF LIFESTYLES}

ABSTRACT: This article investigates how the experience of Biodanza integrative affect the lifestyle of a study group of Biodanza, located in Natal, aiming to seek to understand what is Biodanza experience for participants, while reflecting on the significant changes in life participants' experiences from the integration. The

\footnotetext{
${ }^{1}$ Graduanda do Curso de Educação Física da Universidade Federal do Rio Grande do Norte.

${ }^{2}$ Graduanda do Curso de Filosofia da Universidade Federal do Rio Grande do Norte.

${ }^{3}$ Docente do Curso de Graduação em Educação Física da Universidade Federal do Rio Grande do Norte, Pesquisadora do Grupo Corpo e Cultura de Movimento da UFRN.

${ }^{4}$ Docente do Curso de Graduação em Educação Física da Universidade Federal do Rio Grande do Norte, Pesquisadora do Grupo Corpo e Cultura de Movimento da UFRN e da Rede CEDES/UFRN do Ministério do Esporte.
} 
contribution to the field of Physical Education is the ability to contribute to the few studies addressing the Biodanza, an experience that nurture self-awareness, a sensitivity of body-subject. This is a research-type field study of qualitative nature, and the instrument used a questionnaire with open questions for each of the individual participants (including the facilitator) and a questionnaire specific to only the facilitator. Based on the above proposed objectives and questionnaires were prepared four items, the characterization of groups, socio-economic group investigated the significance and contribution of Biodanza Biodanza in the lifestyles of the group investigated, for reflection and discussion of results. It was found that the Biodanza, change the lifestyles of the participants in a subtle and significant, leading active lifestyles, dynamic, relaxing, holistic, sensitive, meeting of a Physical Education fleeing models for the body to health, but seeks to reconstruct the identity of human beings in society.

KEYWORDS: Life Style. Leisure Activities. Dancing.

\section{INTRODUÇÃO}

O termo Biodanza recebeu influências de Roger Garaudy que conceitua dança como "dançar a vida", e que, segundo Toro (2005), esse conceito vai ao encontro do significado da Biodanza - "Bio" deriva do grego "bios" = vida, restabelecendo o conceito original de dança - movimento de vida, “[...] ligado às emoções e pleno de significado" (TORO, 2005, p. 37).

O criador, Rolando Toro (1924-2010), psicólogo, antropólogo, poeta e escritor chileno, grande humanista, através de experimentos com a dança no hospital psiquiátrico no Chile, observou a grande influência da música na expressão corporal dos doentes mentais internos, ocorrendo variações nos estados de transe destes pacientes. Esse fato proporcionou a criação do primeiro eixo de estudo da Biodanza: IdentidadeRegressão, pois algumas músicas reforçavam o sentimento de identidade de pacientes e outros tipos de música levavam a estados de transe e regressão. Simplificando, um determinado estímulo musical provocava em um indivíduo um movimento corporal, que induzia a uma vivência específica, sempre permeada pela emoção desencadeada. 
O tripé formado por música-movimento-emoção forma a metodologia da Biodanza, a qual consiste em induzir vivências integradoras por meio da música, do movimento e de situações de encontro em grupo, que vão permitir o desenvolvimento de potenciais genéticos, que foram classificados em cinco linhas de vivência (ou modalidades de expressão): vitalidade, sexualidade, criatividade, afetividade e transcendência.

Portanto, o sistema Biodanza “[...] é um sistema de integração humana, de renovação orgânica, de reeducação afetiva e de reaprendizagem das funções originais da vida" (TORO, 2005, p. 33).

A base de toda essa fundamentação teórica que Toro utilizou na Biodanza é o Princípio Biocêntrico, onde coloca o interesse na Vida, compreendendo o universo como um sistema vivo.

A vida não é consequência dos processos atômicos e químicos, mas da estrutura guia da construção do universo. As relações de transformação matéria-energia são os estados de integração da vida. A evolução do universo é, na realidade, a evolução da vida (TORO, 2005, p. 51).

Toro afirma que para compreendermos o termo "Biodanza", é necessário, primeiramente, entendermos o conceito de vivência, cujo termo recebeu influência do filósofo alemão Wilhelm Dilthey. Em alemão, "Erlebnis", definido segundo Dilthey ${ }^{5}$ (apud TORO, 2005, p. 29) como 'algo revelado no complexo psíquico dado na experiência interna de um modo de existir a realidade para um indivíduo', influenciou também na fenomenologia de Merleau-Ponty, na sociologia de Max Weber, dentre outros.

\footnotetext{
${ }^{5}$ DILTHEY, W. Introducione alle scienze dello spirito: ricerca di un fondamento alle scienze della società e della storia. Turim: Paravia, 1949.
} 
O mundo é, não aquilo que eu penso, mas aquilo que eu vivo; eu estou aberto ao mundo, comunico-me, indubitavelmente, com ele, mas não o possuo, ele é inesgotável (MERLEAU-PONTY, 1994, p. 14).

Seguindo esta perspectiva, vivência, adaptada pelo criador do sistema Biodanza (TORO, 2005, p. 30) é uma “[...] experiência vivida com grande intensidade para um indivíduo no momento presente, que envolve a cinestesia, as funções viscerais e emocionais".

Essas vivências apresentam características, tais como: experiência original, anterioridade à consciência, espontaneidade, subjetividade, intensidade variável, temporalidade, emocionalidade, dimensão sinestésica, dimensão ontológica, dimensão psicossomática.

Toro (2005, p. 51) afirma que “[...] os parâmetros da vida cósmica refletem os parâmetros do nosso estilo de vida", ou seja, nossos comportamentos, não se organizam como meios de alcançar fins externos, mas sim como expressão de vida.

Na sociologia de Bourdieu ${ }^{6}$ (apud CASTRO, 2003) este relaciona estilos de vida com as diferentes posições ocupadas pelos indivíduos na sociedade, fato que, Toro (2005) em sua proposta da Biodanza vem a quebrar com essa segmentação, pois acredita que a emoção e o amor, elementos fortemente presentes nas vivências, são intrínsecos de cada ser humano, independente de classe social.

Segundo Bocock ${ }^{7}$ (apud CASTRO, 2003, p. 83) “[...] os indivíduos não devem ser resumidos a segmentos de mercado cooptados e aprisionados pelo sistema".

Refletindo acerca da prática da Biodanza na construção de um estilo de vida mais ativo e integrado, entendemos que o processo resulta da compreensão e

${ }^{6}$ BOURDIEU, P. Gostos de classe e estilos de vida. In: ORTIZ, R. (Org.). BOURDIEU, P. Coleção Grandes Cientistas Sociais. São Paulo: Ática, 1983.

${ }^{7}$ BOCOCK, R.; THOMPSON, K. Social and cultural forms of modernity. Cambridge/Oxford: Polity Press/Basil Blackwell/The Open University, 1993. 
transformação do indivíduo no meio em que atua, desviando o foco do consumismo do estar na moda para a construção do ser reforçado por sua identidade, onde o mesmo é estimulado para uma autonomia em meio à prática do consumo contemporâneo. Segundo Wendell ${ }^{8}$ (apud CASTRO, 2003, p. 84), “[...] afirma a existência, atualmente, de uma tendência a conceber o corpo integrado ao cosmos." Assim, a nosso ver, se traduz essa prática.

Diante da reflexão acima sobre a Biodanza e a conseqüente mudança nos estilos de vida, foi colocado para o grupo investigado, como as vivências integradoras da Biodanza afetam seus estilos de vida?

Considerando-se a questão de estudo apresentada, os objetivos do estudo buscaram compreender o que é vivenciar a Biodanza para os participantes; além de refletir sobre as mudanças significativas na vida dos participantes a partir das vivências integradoras.

Devido à vivência das pesquisadoras no Sistema Biodanza já há algum tempo, surgiu o interesse em trazer para o meio acadêmico a discussão sobre esse sistema e a mudança no estilo de vida, mais conectado consigo mesmo, com o outro e com a natureza ao seu redor, de forma harmônica.

A sociedade na qual vivemos caracteriza-se por uma valorização do que é externo em detrimento do que é interno, seja para comunicar-se com o outro, para se auto-conhecer ou para estar em contato com a natureza.

Nossa sociedade e nossa cultura priorizam o saber intelectual, uma estética ideal, um corpo máquina, um corpo esquecido ou manipulado pelos interesses dominantes, ou seja, o conhecimento e o poder estão acima dos sentimentos, sensações, desejos, necessidades, capacidade de compartilhar a vida e suas múltiplas condições (MORETTI, ALMEIDA, WESTPHAL et al, 2009, p. 350).

${ }^{8}$ WENDELL, E. M. I am my body: a theology of embodiment. New York: Continuum, 1995. 
$\mathrm{Na}$ contramão desse processo que a sociedade caminha, a Biodanza traz uma proposta de viver a vida, sintonizar-se com ela de maneira que favoreça uma auto regulação orgânica, estimule a criatividade, melhore a capacidade de vínculo afetivo, entre outros.

Para a área da Educação Física vemos a importância desta discussão visto que, ainda existem muito poucos trabalhos abordando a Biodanza. Uma vivência que oportuniza um auto-conhecimento, uma sensibilidade do corpo-sujeito.

Lucidamente, Santin nos alerta sobre a delicada tarefa educativa da Educação Física, interpretar a linguagem da corporeidade, as necessidades, os desejos, as emoções que compõem seu quadro lingüístico e que se expressa nos movimentos (NÓBREGA, 2005, p. $81)$.

Dando sequência ao trabalho, mostraremos o percurso metodológico, logo após, os resultados do estudo de campo atrelados à fundamentação teórica, e, as considerações finais.

\section{METODOLOGIA}

O tipo de pesquisa é um estudo de campo, de natureza qualitativa, com um grupo de Biodanza de Natal que se encontra uma vez por mês, aos domingos, das 9h às 17h, com uma pausa de $2 \mathrm{~h}$ para descanso e almoço. Neste grupo investigado há uma variedade quanto aos aspectos, idade, profissão e renda mensal, sendo o gênero invariável (a maioria mulheres). Investigaremos como a vivência da Biodanza afeta os estilos de vida dos participantes.

Os estudos de campo buscam descrever com certa profundidade populações e fenômenos e mesmo explorar acerca de fatores que influenciam na ocorrência dessas características (GIL, 2006, p. 135). 
A técnica empregada neste trabalho foi um questionário com perguntas abertas, realizado no dia 18 de abril (domingo) no horário da pausa (almoço e descanso) do grupo, de forma individual, no próprio local onde se realiza a prática. A escolha do dia e do horário foi feita pelo grupo, mediante algumas sugestões dadas pela entrevistadora.

As perguntas foram primeiramente formuladas pelas entrevistadoras com a orientação da professora da disciplina Sociologia do Esporte e das Práticas Corporais, Maria Isabel Brandão de Souza Mendes, no dia 15 de abril, dirigidas a um grupo de Biodanza de Natal, cujo encontro se dá uma vez ao mês (domingo), das $9 \mathrm{~h}$ às $17 \mathrm{~h}$ (pausa de 2h, almoço e descanso) em uma sala com privacidade, arejada, espaçosa, com piso amortecedor (tatame), localizada em uma escola que hoje é ponto de cultura do grupo artístico Facetas, Mutretas e Outras histórias, de Natal.

Antes do encontro com os participantes de Biodanza, houve um encontro entre as entrevistadoras e a facilitadora dessa prática, trazendo um olhar sensível e experiente, visto que ela é facilitadora há 25 anos e compartilha as vivências com esse grupo entrevistado há uns cinco anos.

As perguntas foram elaboradas individualmente para todos (inclusive para a facilitadora) e algumas perguntas específicas somente para a facilitadora, visando com isso, responder a questão de estudo e os objetivos (perguntas individuais), ou seja, como a Biodanza influencia na mudança dos estilos de vida dos que participam dessa prática e o que é a vivência para os mesmos, assim como, responder algumas caracterizações propostas pela professora da disciplina, para esse trabalho, que foram direcionadas especificamente a facilitadora, tais como tipos de espaços, tempo dedicado à prática e a frequiência, características relacionadas à prática dos exercícios e aprendizagem, gestão do corpo e representações. As perguntas individuais a todos os participantes abrangem tanto os dados pessoais, como idade, profissão e renda, como perguntas mais pertinentes 
à questão central deste estudo de campo, resultando em cinco perguntas chaves para a obtenção da reflexão através dos quadros criados.

A análise qualitativa depende de muitos fatores, tais como a natureza dos dados coletados, a extensão da amostra, os instrumentos da pesquisa e os pressupostos teóricos que nortearam a investigação. Pode-se, no entanto, definir esse procedimento como uma sequência de atividades, que envolve a redução dos dados, a categorização desses dados, sua interpretação e a redução do relatório. (GIL, 2006, p. 133)

Diante disso, a aplicação do questionário ocorreu no dia 18 de abril de 2010 (domingo) quando o grupo encontrou-se para mais uma vivência no espaço falado anteriormente. Nesse dia só tinha mulheres no grupo. Antes de iniciar a vivência com a facilitadora, foi colocado para o grupo algumas perguntas a fim de que as entrevistadas se sentissem o mais a vontade possível quanto à forma (perguntas orais ou escritas) e o momento mais adequado (antes das atividades, na hora da pausa ou no final do dia). Foi consenso de todas, a escolha pela forma escrita e pelo momento adequado, o da pausa. O critério de escolha para as pessoas entrevistadas foi o fato de estarem participando da vivência no dia (18 de abril, domingo) da entrevista, e essas pessoas, puderam escolher se queriam responder ou não.

Chegado o momento da pausa do grupo, cada uma recebeu o questionário com as devidas perguntas e de forma livre escolheram o local e a forma de se acomodarem. Nesse dia havia 5 participantes e mais a facilitadora, todas foram entrevistadas. Todas ficaram na sala em que ocorre a vivência e o instante ritualístico da pausa, algumas sentadas e outras deitadas, sendo que duas pessoas ficaram perto uma da outra. Essa aproximação acabou gerando trocas de informações e questionamentos entre elas a respeito da forma como cada uma respondeu o devido questionário, gerando dúvidas e surpresas de qual a resposta mais adequada, buscando na entrevistadora as respostas 
dessas inquietações, onde, a mesma frisou a riqueza da individualidade de cada sujeito. Essas mesmas pessoas, após entregarem o questionário, deram continuidade a mais discussões que não eram pertencentes ao questionário, levando-as a se surpreenderem sobre questões que não tinham parado para refletirem intensamente.

Outro momento relevante para este trabalho foi no fechamento da vivência, que já se tornou um ritual para o grupo, em que conversam sobre as questões relacionadas com a aula do dia, e, com isso, todas as participantes (inclusive a própria facilitadora) foram enfáticas ao afirmarem o quanto o questionário proporcionou reflexões tanto do seu dia-a-dia quanto da sua própria vivência no período da tarde (pós-entrevista), lembrando que houve a vivência pela manhã também.

\section{RESULTADOS E DISCUSSÃO}

Os resultados serão divididos em quatro itens: o primeiro configura-se quanto à caracterização dos diferentes grupos existentes na Biodanza, respondidas somente pela facilitadora, e é relativo às caracterizações propostas no roteiro fornecido pela professora da disciplina: tipos de espaço, tempo dedicado à prática e a frequência, características relacionadas à prática dos exercícios e aprendizagem, gestão do corpo (comportamentos, regras e ritos) e aspectos das representações; o segundo refere-se ao perfil sócio-econômico das pessoas entrevistadas (facilitadora + todas as participantes); e o terceiro e o quarto, corresponde às perguntas individuais destinadas a todas as participantes presentes (incluso a facilitadora também), chamadas de questões-chaves, nas quais buscamos refletir sobre a influência da Biodanza na mudança dos estilos de vida das participantes. 
O procedimento dado à análise dos resultados variou, então, de acordo com as divisões presentes no parágrafo acima, ou seja, sobre a metodologia do Sistema Biodanza e o perfil sócio-econômico, e as sensações e percepções dos entrevistados que vivenciam essa prática. Para o primeiro item, notou-se a repetição de três palavraschave: grupos regulares, grupos de maratonas e o grupo investigado, presentes em todas as caracterizações (tipos de espaço, tempo dedicado à prática, freqüência, gestão do corpo e representações), ocorrendo diferenças e semelhanças entre os grupos. Para o segundo item, o perfil sócio-econômico, com uma variedade de profissões e salário. E o terceiro e quarto item, são as sensações e percepções das entrevistadas, onde, no terceiro item, tentamos responder a um dos objetivos quando se refere à compreensão do que é a vivência para elas, e no quarto item, tentamos responder a outro objetivo, se referindo a contribuição da Biodanza na mudança dos estilos de vida das participantes. Tanto na caracterização dos grupos (primeiro item) como nas sensações e percepções das entrevistadas (terceiro e quarto item), as respostas foram colocadas em forma de palavras-chaves que chamaremos de categorias, nas quais estão presentes os aspectos desta.

Os resultados estão apresentados em forma de itens que são respectivamente: a caracterização dos grupos existentes na Biodanza sob diversos aspectos, o perfil sócioeconomico das entrevistadas, quais significados da vivência e quais as contribuições da Biodanza nos estilos de vida das entrevistadas. Para cada item haverá uma discussão entre o que foi coletado e a fundamentação teórica. Os quadros relativos a cada item se encontram nos anexos.

\section{Caracterização dos Grupos}


Este item trata das caracterizações dos grupos que dizem respeito à metodologia da Biodanza, respondidas exclusivamente pela facilitadora do grupo investigado. Para isso foram criados três grupos que correspondem aos grupos existentes na Biodanza (grupos regulares e de maratonas), incluindo o grupo investigado nesse estudo de campo.

\section{Grupos Regulares}

Podemos perceber que os grupos regulares se reúnem em locais urbanos, com privacidade e conforto, semanal, permeado por conversas e vivências, acompanhado de um aparelho de som. Notamos então um ambiente propício ao relaxamento, a entrega do ser, no meio coletivo seguro e acolhedor.

Podemos notar o elo entre as categorias prática de exercícios e aprendizagem, e a gestão do corpo, onde vemos que o Princípio Biocêntrico, base teórica da Biodanza, nos faz perceber outros modos de sentir as experiências com o grupo e consigo, levando-nos a uma auto-regulação orgânica, reconhecendo e descobrindo nossos limites e possibilidades, permeados pela metodologia música-movimento-emoção.

Outra categoria é a presença dos mitos e arquétipos nas aulas e movimentos, baseados em Carl Jung, nos levando a experiências originais da vida e que mantém íntima relação com o Princípio Biocêntrico, nos mostrando que nada está separado ou estanque e sim em contínua transformação e evolução. Um exemplo dessas posições geratrizes é a roda que se caracteriza como um rito, no início e no final das vivências. A roda simboliza o círculo, simbologia universal.

\section{Grupos de Maratonas}


Podemos apontar algumas diferenças e semelhanças entre este grupo (grupo de maratonas) e o grupo anterior (grupos regulares), iniciando-se com duas diferenças bem acentuadas, que ocorrem nas categorias, tempo dedicados à prática e sua frequência, com encontros ocasionais aos finais de semana (inicia-se na sexta e finaliza no domingo). Essas particularidades desse grupo verificam-se nos encontros ocorridos ao longo do ano pelo mundo todo, como por exemplo, o Encontro Nordestino de Biodanza. Nesses encontros, durante alguns momentos, por exemplo no encerramento da abertura e nas palestras com Toro, há vivências e demonstrações de exercícios que podem ser observados (às vezes filmados), tendo uma flexibilidade maior quanto a poder observar, ao mesmo tempo em que, nesses mesmos encontros, durante as oficinas, já não podem ser observadas, seguindo a mesma premissa que o grupos regulares.

Os espaços onde ocorrem às vivências são mais flexíveis, podendo ser em locais urbanos e não-urbanos, ambos podem ser em locais abertos ou fechados ao público.

Quanto aos pontos semelhantes entre os dois grupos (regulares e maratonas), aparecem às categorias, a prática dos exercícios e aprendizagem, os ritos e as representações, relativas ao princípio biocêntrico e a metodologia música-movimentoemoção, e a presença dos arquétipos e mitos (Carl Jung), onde os indivíduos são estimulados a sua auto-regulação. O rito, simbolizado pela roda também aparece fortemente aqui nesses grupos.. Essas categorias são os pontos norteadores do Sistema Biodanza presentes em qualquer grupo, inclusive no grupo investigado, que veremos a seguir.

\section{Grupo Investigado}

Nesse grupo investigado, foco do estudo de campo, podemos perceber alguns pontos em comum com os outros grupos vistos anteriormente (regulares e de 
maratonas), como, o Princípio Biocêntrico e o trinômio música-movimento-emoção, os ritos e as representações arquetípicas, confirmando mais uma vez como elementoschaves do Sistema Biodanza.

Na Idade Média, o corpo com desejos é visto como sinônimo de pecado, sendo este corpo uma barreira para a salvação, inclusive a sexualidade. O corpo aqui é visto como uma sacralidade, enquanto na Biodanza a Vida é sacralizada, tendo como fundamentação teórica o Princípio Biocêntrico. Na Idade Média, vingava o Princípio Antropocêntrico.

A idade média traz como uma característica principal a sacralização do corpo, onde o mesmo se torna sinônimo de pecado. [...] A grande valorização do religioso promoveu a demonização dos desejos, entre eles muitas coisas relacionadas ao corpo, inclusive a sexualidade, devido à idéia de que o corpo é um dos obstáculos à descoberta da verdade e salvação Sant'anna ${ }^{9}$ (apud FRANCO \& JATOBÁ, 2007).

A Biodanza vem a ser uma proposta sobre o corpo de forma integrada,

diferentemente que o discurso racionalista propõe.

No discurso científico contemporâneo, o corpo é pensado como uma matéria indiferente, simples suporte da pessoa. Ontologicamente distante do sujeito, torna-se um objeto à disposição sobre o qual agir a fim de melhorá-lo, uma matéria-prima na qual se dilui a identidade pessoal, e não mais uma raiz de identidade do homem. Duplo do homem, mas sem cláusula de consciência, senão ao contrário, pela evocação dos preconceitos, do conservadorismo ou da ignorância dos que desejam fixar limites à fragmentação da corporeidade humana. (BRETON, 2008, p. 15)

Portanto, a Biodanza trabalha com o corpo integrado, uma visão do homem ligado aos seus instintos primordiais, unificando-o consigo, com o outro e o meio em volta.

9 SANT'ANNA, Denise Bernuzzi de. É possível realizar uma história do corpo?. In: SOARES, Carmen Lúcia (Org.). Corpo e história. Campinas: Autores Associados, $2^{\mathrm{a}}$ ed. 2004. p. 3 - 23. 
Podemos ver duas categorias que diferem dos grupos regulares e de maratonas: o tempo dedicado à prática e a frequência, ambos ocorrem através de um acordo entre a facilitadora e o grupo, haja visto que é um grupo pequeno e com pouco fluxo de pessoas novas, portanto se caracteriza com um encontro mensal, durante todo o domingo, uma espécie de "mini-maratona" denominado pela própria facilitadora.

Entre os grupos regulares e este em foco (grupo investigado) há dois pontos em comum, um relativo ao espaço onde é realizada a prática (espaços urbanos, confortáveis e com privacidade e aparelho de som); e o outro relativo à questão de não poder observar a vivência, acompanhada do estímulo dado pela facilitadora aos alunos quanto à auto-regulação dos mesmos.

Podemos notar algumas particularidades nesse grupo investigado em relação aos outros dois grupos (regulares e de maratonas), como, a adição de outras técnicas e dinâmicas (danças circulares, teatro) pela facilitadora, devido as suas experiências através de participações em oficinas e grupos de danças circulares e teatro, e sua formação acadêmica em artes cênicas; outra particularidade é a proposta de um mito como temática de algumas aulas; finalizando mais uma particularidade, o rito de confraternização e de despedida em todas as suas aulas, onde o primeiro é simbolizado através do almoço e o segundo através de conversas ao final das aulas para quem quiser expor algumas sensações e insights ocorridos na aula ou na semana.

“A gestualidade refere-se às ações do corpo quando os atores se encontram: ritual de saudação ou de despedida [...]" (LE BRETON, 2009, p. 44). Cada grupo tem seus modos específicos de ritual de saudação, a gestualidade do corpo é um fator preponderante na Biodanza, cheios de significados. Exemplificando, a facilitadora cita:

[...] todas as aulas começam e terminam com uma roda, chamadas de "roda de abertura" e "roda de ativação" quando o aluno sai dos estados provocados pela aula e volta ao "mundo real", digamos assim. 
No nosso grupo, em função da forma de nossos encontros, o almoço acabou se tornando um rito de confraternização e o final da aula um rito de despedida, quando nos sentamos e fechamos as questões relacionadas com a aula do dia [...]

Portanto, podemos perceber a riqueza de significados durante as vivências desse grupo, a variedade de contribuições no tocante à gestão desse corpo, de forma sensível e profunda.

\section{Perfil Sócio-econômico do Grupo Investigado}

Neste item investigamos o perfil das entrevistadas quanto à idade, a profissão e a renda mensal.

Podemos notar em relação à faixa etária, uma variedade, partir dos 30 anos em diante presentes neste grupo. O fato de não existir adolescentes ou crianças não significa que a Biodanza é realizada somente para adultos, muito pelo contrário, atualmente a Biodanza atende todas as faixas etárias, sendo que para cada faixa etária existe uma metodologia, onde neste grupo a facilitadora trabalha com uma metodologia voltada para a faixa etária composta por adultos.

Da mesma forma que a idade apresentou variações, a categoria relacionada a profissões exercidas pelos alunos e pela facilitadora também apresentou uma variedade, encontrando profissionais da saúde, da arte, do ensino.

Finalizando este item relacionado ao perfil sócio-econômico, apresentamos a última categoria, que trata da questão financeira dos alunos e da facilitadora, onde novamente vemos uma variação nas condições econômicas destes, com a ocorrência desde um salário mínimo e se estendendo acima de cinco salários mínimos. Podemos perceber que esta prática não se fecha a determinadas camadas sociais, mas sim abrange 
todas elas, de modo que a atenção ao corpo de forma sensível, profunda, integrada e coletiva é buscada pelo ser humano, independente da sua condição financeira.

\section{Significados da Biodanza para o Grupo Investigado}

Este item, que se constitui em um dos objetivos do trabalho, aborda quais os significados da vivência para as entrevistadas, colocados em forma de categorias acompanhadas por diversos aspectos.

Este item trata do significado da vivência para as entrevistadas, onde podemos notar na categoria, ser eu mesma, a possibilidade que a vivência acarreta aos indivíduos entrevistados de se libertar de padrões de comportamento, vivenciando de forma autêntica e autônoma os seus movimentos sendo ela mesma no mundo, com sua identidade desvelada e ao mesmo tempo sentindo-se acolhida. Um fato interessante para os profissionais de Educação Física repensarem quanto ao padrão ideal de corpo, tão exacerbado nessa área, e que tem sido motivo de estudos por educadores físicos conscientes da diversidade de corpos existentes na sociedade, como podemos ver no texto Do ideal de robustez ao ideal de magreza: Educação Física, saúde e estética (MENDES, 2009). Nesse texto a autora nos convida a pensarmos em cuidarmos desse corpo, respeitando a singularidade de cada um na busca pela saúde e não por modismos ou convenções impostas pela sociedade.

[...] um dos desafios para os profissionais da Educação Física é reconhecer a diversidade de corpos existentes na sociedade e tematizar os cuidados com o corpo em busca de saúde sem se fixar em um padrão ideal (MENDES, 2009, p. 177).

Na Biodanza, vemos através dos depoimentos, o quanto é valorizado o indivíduo na sua liberdade (sem rótulos), na sua identidade, e esta mesma é um componente da 
vivência. Mas na sociedade é preconizado um padrão de corpo onde mostra a importância de sermos todos iguais,

Somos seres únicos, até mesmo gêmeos idênticos se diferenciam ao longo do seu processo de maturação. Imagine o impacto que um padrão estético ideal pode causar em homens, mulheres, crianças ou adolescentes. Que conseqüências pode causar para a sociedade? O que se faz quando alguém diz: 'Fique nu... Mas seja magro, bonito e bronzeado' Foucault ${ }^{10}$ (apud JATOBÁ e FRANCO, 2007).

Segundo Figueira ${ }^{11}$ (apud JATOBÁ e FRANCO, 2007), 'na sociedade contemporânea, o corpo é o local de construção de identidades'. Podemos observar essa construção, nas entrevistas, nas categorias novas possibilidades e ser eu mesma, como também, na própria teoria do sistema Biodanza, que tem como base metodológica às vivências integradoras da identidade. Essa integração da identidade na Biodanza dá sentido e significado ao corpo, que podemos chamar de corpo-sujeito em contraposição a um corpo-objeto. O corpo, nos padrões da sociedade "está sendo manipulado de uma forma meramente mercadológica, sendo tratado como um mero objeto de consumo" (JATOBÁ e FRANCO, 2007).

Na categoria novas possibilidades, percebemos nas entrevistas que a vivência da Biodanza traz significados quanto à descoberta de novos caminhos a partir da percepção de seus limites e bloqueios, proporcionando também uma abertura a criatividade das alunas. Esse fato nos mostra que a vivência provoca percepções mais profundas para dentro de si mesmo, uma espécie de investigação por caminhos tortuosos, mas necessários para que o dia-a-dia se torne mais fluido. Esse dia-a-dia pode ser estendido na integração com o outro, com o entorno e com o cosmos, como vemos nesta mesma

\footnotetext{
${ }^{10}$ FOUCAULT, Michel. Microfísica do poder. Rio de Janeiro: Graal, 1986. 174 p.

11 FIGUEIRA, M. L. M. Revista capricho e a produção de corpos adolescentes femininos. In: FELIPE, J.; GOELLNER, S. V.; LOURO, G. L.(Org.). Corpo, gênero e sexualidade: um debate contemporâneo na educação. Petrópolis: Vozes, 2003. p. 124 -135.
} 
categoria apontamentos para esses contatos que são representados pela roda em direção a totalidade.

Essas percepções estão entrelaçadas com outras categorias, como a experiência espacial e a experiência afetiva, onde aparecem à fluidez do movimento e rio de amor, respectivamente.

Uma outra categoria formada é a experiência sensorial, que em seus aspectos, apontados pelas entrevistadas nos mostra a ligação com a percepção de se sentir vivo, e como podemos sentir a si mesmo e ao outro, através da música, do olhar, da respiração, do toque. Essa riqueza de informações nos mostra a variedade de sensações que esta prática provoca, em consonância com o autor abaixo, que destacamos o seguinte trecho:

A configuração dos sentidos, a tonalidade e contorno do seu desenvolvimento são de natureza não somente fisiológica, mas também social. A cada instante decodificamos sensorialmente o mundo transformando-o em informações visuais, auditivas, olfativas, táteis ou gustativas. Assim, certos sinais corporais escapam ao controle da vontade ou da consciência do ator, mas nem por isso perdem sua dimensão social e cultural [...] (LE BRETON, 2008, p. $55)$.

Portanto o significado da Biodanza perpassa essas várias dimensões citadas acima não só nesta categoria, experiência sensorial, mas em todas elas, de modo que esta prática segue o percurso que preconiza o corpo, movimento, expressão, levando o indivíduo a trocas afetivas saudáveis e revitalizadoras.

\section{Contribuição da Biodanza nos Estilos de Vida do Grupo Investigado}

Este item busca responder a questão central do estudo de campo, ou seja, quais as contribuições que a Biodanza traz nos estilo de vida das entrevistadas.

Notamos em uma das categorias, auto-conhecimento, a contribuição que a Biodanza traz nos estilos de vida das praticantes indo ao encontro de uma maior 
consciência individual compartilhada no coletivo, de forma saudável, sem se deixar influenciar pelas normas de conduta ou de beleza. Dessa forma, não há a preocupação por um modelo de corpo exigido pela sociedade, exigência esta que podemos observar, quando Le Breton fala que este corpo é “[...] como simulacro do homem por meio do qual é avaliada a qualidade de sua presença e no qual ele mesmo ostenta a imagem que pretende dar aos outros" (BRETON, 2008, p. 31). Portanto, a Biodanza, vem a promover, uma:

[...] conexão com a própria energia vital, de forma harmônica e dinâmica, considerando os aspectos físicos e psíquicos, que leva a um bem-estar que está relacionado com o estilo de viver, de 'con-viver' com os seres e de se integrar ao universo (GÓIS e RIBEIRO, 2008, p. 45).

Há uma supervalorização da aparência na sociedade onde o "ter" supera o "ser" levando a uma desumanização e a um corpo-objeto, fato que a Biodanza enfatiza o contrário, onde a humanização consigo, com o outro e com o entorno é uma constante em uma relação fenomenológica com o corpo.

O estilo de vida da contemporaneidade, marcados pela cultura do ter, cultura da quantidade, cultura do rápido e eficiente, tem produzido inúmeras doenças e sintomas nos seres humanos (NORONHA).

Em se tratando da questão da humanização, há a categoria que aparece relacionada à humanização consigo, com o outro e com o meio, na qual seus aspectos nos mostram uma flexibilidade maior diante da vida, aceitando que esta não é imutável, e sim propícia a mudanças, encarando seu ambiente de trabalho de forma mais leve, estando mais brincalhona. Esses aspectos nos mostram um estilo de vida mais dinâmico, menos estressante, aceitando o outro com suas particularidades e diferenças.

Os sujeitos, ao reunirem-se para vivenciar ou apreciar determinada prática corporal, contribuem com a construção do espaço social. 
Espaço esse que vai sendo construído individual e coletivamente (MENDES e NÓBREGA, 2009, p. 7).

Esse espaço, portanto, é construído de forma afetiva, como vemos em outra categoria formada, tornou-se mais afetiva, de forma que essa afetividade é expressa de várias formas, seja através de abraços mais demorados, seja através de olhares mais sinceros, seja através de atitudes prazerosas e tranquilas na vida. Cada um expressando e sentindo a sua maneira a sensibilidade diante da vida, como destacamos no trecho abaixo.

A linguagem sensível é revelada pala movimentação do corpo no tempo e no espaço de cada indivíduo e da comunidade. Somos capazes de criar e recriar, e, ao mesmo tempo em que nos expressamos, conseguimos nos comunicar (MENDES e NÓBREGA, 2009, p. 6).

Outra categoria que aparece nesse item relativo a contribuição da Biodanza nos estilos de vida, é prontidão com a vida, onde aparece uma proposta de viver a vida no aqui e agora, como Toro propõe na Biodanza, de forma que seja prazerosa, que traga um bem-estar, que viva a vida positivamente. Essa positividade pode ser notada em um dos aspectos trazidos nesta categoria em que há o reconhecimento das conquistas e a valorização destas, enfrentando as dificuldades. Diferentemente do que a sociedade preconiza:

[...] sociedade contemporânea, ainda marcada por estilos de vida geradores de ansiedade e de estresse. Observamos a predominância da competitividade e da grande valorização do consumo e da imagem, com repressão dos sentimentos, das emoções e dos instintos (GÓIS e RIBEIRO, 2008, p. 1).

Esta prontidão com a vida tem uma íntima relação com outra categoria formada, auto-confiança, fortalecendo a identidade do indivíduo como é no mundo, com isso se conhecendo mais no tocante aos seus medos, seus sentidos, suas emoções. Mais 
desenvoltura para compartilhar carinhos, toques, olhares com o outro sem preconceitos, portanto nos mostra um ser humano mais integrado consigo, com o outro e com o meio. Diferentemente da proposta de Descartes, "a formulação do cogito por Descartes prolonga historicamente a dissociação implícita do homem de seu corpo despojado de valor próprio" (BRETON, 2008, p. 18), a Biodanza busca a identidade do indivíduo nas vivências, valorizando o valor de cada um, sendo único.

A identidade e movimento associados ao amor constituem uma presença sensível de vida no mundo, com possibilidades amplas de alterações de referenciais presentes nos relacionamentos interpessoais pautados em modelos bélicos; de expansão da ternura e da restauração do sentido pleno de viver com o outro, em comunidade e em comunhão com a totalidade. (GÓIS e RIBEIRO, 2008, p. 51)

A Biodanza vem a trazer uma unificação da identidade do indivíduo em uma sociedade fragmentada, propõe uma relação fenomenológica de corporeidade do indivíduo e consequentemente um estilo de vida. Uma transgressão de valores em uma sociedade que preconiza através de vários veículos de comunicação a fragmentação, como Le Breton aponta.

A comunicação sem rosto - sem carne - favorece as identidades múltiplas, a fragmentação do sujeito comprometido em uma série de encontros virtuais para os quais a cada vez ele endossa um nome diferente, e até mesmo uma idade, um sexo, uma profissão escolhidos de acordo com as circunstâncias. [...] esse paraíso necessariamente não tem corpo (BRETON, 2008, p. 24).

Um ponto interessante que podemos fazer relação entre a Biodanza e a área da Educação Física é sobre a saúde como uma forma de conviver harmoniosamente consigo, com os outros, com a natureza e com o cosmos, ou seja, em um mundo melhor, fato que na área da Educação Física, podemos perceber, a partir de uma visão crítica da autora sobre esse modelo de saúde no texto Do ideal de robustez ao ideal de magreza: 
Educação Física, saúde e estética Mendes ${ }^{12}$ (apud CARVALHO, 1995, p. 185), o quanto que a compreensão sobre a saúde ainda é vinculada a um padrão de beleza ideal; além disso, a atividade física ainda é muito associada a apenas saúde na área da Educação Física, enquanto que as entrevistadas colocam outros pontos além da saúde, como, vivência prazerosa, auto-conhecimento, mudanças de dentro para fora, por exemplo.

\section{CONSIDERAÇÕES FINAIS}

Conforme vimos os resultados, a influência da Biodanza nos estilos de vida das pessoas que vivenciam esta atividade atinge todos os aspectos da sua vida, de forma profunda, sensível, ao longo do tempo, em conjunto com outras pessoas, em contato consigo mesmo e com o meio.

Não existindo um ideal estético preestabelecido, as motivações que levam as pessoas a praticarem Biodanza e consequentemente um estilo de vida mais leve, autêntico, prazeroso, integrado, proporciona o autoconhecimento, deixando de supervalorizar os valores materiais em detrimento da sua própria Vida. Isso tudo mediante vivências que estimulam a saúde, a vitalidade, à criatividade, à afetividade, à transcendência, entre os diferentes gêneros, classes e gerações, e também a importância de como estes mesmos indivíduos estabelecem seu convívio com a natureza fazendo florescer seus sentimentos com diferentes grupos sociais.

\footnotetext{
12 MENDES, M. I. B. de S. Do ideal de robustez ao ideal de magreza: Educação Física, saúde e estética. Revista Movimento, Porto Alegre, v. 15, n 04, p. 175-191, outubro/dezembro de 2009.
} 
Na Biodanza, o processo de integração ocorre por meio da estimulação primordial de conexão com a vida, através das vivências, permitindo ao indivíduo integrar-se a si mesmo, ao outro e à natureza ao seu redor.

Essa forma de vivenciar a vida, de senti-la, nos leva a reflexões de que estilos de vida são criados no dia-a-dia. Estilos de vida que abarcam o estresse, a correria, a competição, o superficial, se encaixam na contribuição que a Biodanza promove aos participantes desta prática? Bem, pelas discussões ao longo desse artigo, notamos que esta prática provoca uma outra forma de olhar e sentir a vida, consequentemente estilos de vida mais em consonância consigo, com o outro e com o meio. Com isso, não há a pretensão de afirmar que esta é a única maneira de buscarmos novas formas de viver, diante da variedade de opções que temos no contexto de práticas corporais, mas sim alguns apontamentos e reflexões baseados nas respostas de biodançantes, fato que também poderá propiciar novas interpretações, novos olhares de outras pessoas que passearem por este artigo.

\section{REFERÊNCIAS}

CARVALHO, Y. M. O mito da atividade física e saúde. São Paulo: Hucitec, 1995.

CASTRO, Ana Lucia. Culto ao Corpo e sociedade: mídia, estilos de vida e cultura de consumo. São Paulo: Annablume; FAPESP, 2003.

GARAUDY, Roger. Dançar a vida. 4. ed. Rio de Janeiro: Nova Fronteira, 1980.

GIL, A. C. Métodos e técnicas de pesquisa social. 5. ed. São Paulo: Atlas, 2006.

GÓIS, C. W. de L. e RIBEIRO, K. G. Biodança, saúde e qualidade de vida: uma perspectiva integral do organismo. Revista Pensamento Biocêntrico, Pelotas, n.10 jul/dez 2008. Disponível em: < http://www.pensamentobiocentrico.com.br/content/edicoes/revista-10-03.pdf $>$. Acesso em: 27 fev. 2011. 
JATOBÁ, V. e FRANCO, L. W. Análise reflexiva do corpo cultural. Revista Digital Lecturas: E.F. y Deportes, Buenos Aires, n. 109, v.12, junio de 2007. Disponível em:< http://www.efdeportes.com/efd109/analise-reflexiva-do-corpo-cultural.htm>. Acesso em: 29 maio 2010.

LE BRETON, D.. Adeus ao corpo: Antropologia e sociedade. 3. ed. Campinas: Papirus, 2008. Disponível em: $<\quad$ http://books.google.com.br/books?hl=ptBR\&lr=lang_pt\&id=tuop9RFGnN4C\&oi=fnd\&pg=PA9\&dq=sociologia + do + corpo,+ Le +Breton\&ots=n9DeV3fxno\&sig=ONTJo8c9REhkBR5J4M91xApjW5o\#v=onepage\&q $=$ sociologia $\% 20 \mathrm{do} \% 20$ corpo $\% 2 \mathrm{C} \% 20 \mathrm{Le} \% 20 \mathrm{Breton} \& \mathrm{f}=$ false $>$. Acesso em: 28 maio 2010.

Vozes, 2009.

A sociologia do corpo. Tradução de Sonia M. S. Fuhrmann. 3. ed. Petrópolis:

MENDES, M. I. B. de S. e NÓBREGA, T. P. da. Cultura de movimento: reflexões a partir da relação ente corpo, natureza e cultura. Revista Pensar a Prática, v. 12, n.2, p. 1-10, maio/ago. 2009.

MERLEAU-PONTY, Maurice. Fenomenologia da percepção. [tradução Carlos Alberto Ribeiro de Moura]. 2. ed. São Paulo: Martins Fontes, 1994.

MORETTI, A. C. , ALMEIDA, V. , WESTPHAL, M. F. , BÓGUS, C. M. Práticas corporais/ atividade física e políticas públicas de promoção da saúde. Revista Saúde Soc. São Paulo, v. 18, n. 2, p. 346-354, 2009. Disponível em: < http://www.scielo.br/pdf/sausoc/v18n2/17.pdf >. Acesso em: 24 fev. 2011.

NÓBREGA, Terezinha Petrúcia da. Corporeidade e educação física do corpo-objeto ao corpo-sujeito. 2. ed. Natal: EDUFRN Editora da UFRN, 2005.

NORONHA, S. Biodança e Saúde. Disponível em:< http://www.biodanzabh.com/arq/biodancaesaude.pdf. Acesso em: 02 abr 2010.

TORO, Rolando. Biodanza. 2. ed. São Paulo: Olavobras, 2005.

\section{Endereço das Autoras:}

Maria Isabel Brandão de Souza Mendes

Rua das Algas 2190 - Ponta Negra

Rio Grande do Norte - Natal

Cep: 59.090-410

Endereço Eletrônico: isabelmendes@ufrnet.br 